\title{
BMJ Open Electronic nicotine delivery system use behaviour and loss of autonomy among American Indians: results from an observational study
}

\author{
Dana Mowls Carroll, ${ }^{1}$ Theodore L Wagener, ${ }^{2}$ David M Thompson, ${ }^{3}$ \\ Lancer D Stephens, ${ }^{4}$ Jennifer D Peck, ${ }^{3}$ Janis E Campbell, ${ }^{3}$ Laura A Beebe ${ }^{3}$
}

To cite: Carroll DM, Wagener TL, Thompson DM, et al. Electronic nicotine delivery system use behaviour and loss of autonomy among American Indians: results from an observational study. BMJ Open 2017;7:e018469. doi:10.1136/ bmjopen-2017-018469

\section{- Prepublication history for} this paper is available online. To view these files, please visit the journal online (http://dx.doi. org/10.1136/bmjopen-2017018469).

Received 5 July 2017

Revised 2 November 2017

Accepted 3 November 2017

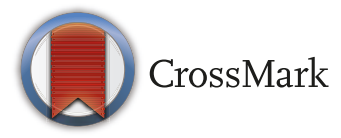

${ }^{1}$ Tobacco Research Programs, University of Minnesota, Minneapolis, Minnesota, USA ${ }^{2}$ Oklahoma Tobacco Research Center, University of Oklahoma Health Sciences Center, Oklahoma City, Oklahoma, USA ${ }^{3}$ Department of Biostatistics and Epidemiology, College of Public Health, University of Oklahoma Health Sciences Center, Oklahoma City, Oklahoma, USA ${ }^{4}$ Department of Health Promotion Sciences, College of Public Health, University of Oklahoma Health Sciences Center, Oklahoma City, Oklahoma, USA

Correspondence to Dr Dana Mowls Carroll; dcarroll@umn.edu

\section{ABSTRACT}

Objective American Indians (Al) have a high prevalence of electronic nicotine delivery system (ENDS) use. However, little information exists on (ENDS) use, either alone or in combination with cigarettes (dual use), among Al. The objective of this small-scaled study was to examine use behaviours and dependence among exclusive ENDS users and dual users of Al descent. Exclusive smokers were included for comparison purposes.

Setting Oklahoma, USA.

Participants Adults of Al descent who reported being exclusive ENDS users $(n=27)$, dual users $(n=28)$ or exclusive cigarette smokers $(n=27)$.

Measures Participants completed a detailed questionnaire on use behaviours. The Hooked on Nicotine Checklist (HONC) was used to assess loss of autonomy over cigarettes and was reworded for ENDS. Dual users completed the HONC twice. Sum of endorsed items indicated severity of diminished autonomy. Comparisons were made with non-parametric methods and statistical significance was defined as $\mathrm{P}<0.05$.

Results Median duration of ENDS use was 2 years among ENDS users and 1 year among dual users. Most ENDS and dual users reported $<20$ vape sessions per day $(72.0 \%$ vs $72.0 \%$ ) with $\leq 10$ puffs per vape session $(70.4 \%$ vs $69.2 \%)$. Severity of diminished autonomy over ENDS was similar among ENDS and dual users (medians: 4 vs $3 ; P=0.6865$ ). Among dual users, severity of diminished autonomy was lower for ENDS than cigarettes (medians:

3 vs $9 ; \mathrm{P}=<0.0001)$. Comparing ENDS users with smokers ENDS users had a lower severity of diminished autonomy (4 vs $8 ; P=0.0077$ ). Comparing dual users with smokers, median severity of diminished autonomy over cigarettes did not differ ( $P=0.6865)$.

Conclusions Severity of diminished autonomy was lower for ENDS than cigarettes in this small sample of Al. Future, adequately powered studies should be conducted to fully understand ENDS use patterns and dependence levels in this population.

\section{INTRODUCTION}

Electronic nicotine delivery systems (ENDS), also referred to as e-cigarettes and vaping devices, are a line of relatively new tobacco

\section{Strengths and limitations of this study}

- This is the first study to provide use and dependence data on electronic nicotine delivery system (ENDS) users of American Indian (Al) descent, a minority population in the USA with high rates of tobaccorelated disease and often under-represented in epidemiologic and clinical research.

- This study describes a novel method for assessing loss of autonomy, a core feature of dependence, in ENDS users by adapting the Hooked on Nicotine Checklist.

- Due to the small sample size, conveniencebased sampling approach and eligibility criteria, generalisations to all Als in Oklahoma should be made with caution.

- This study relied on self-report and thus prone to recall bias.

products that heat a solution, often containing nicotine and flavourants, to generate an aerosol. Although ENDS aerosol is not harmless, it generally contains fewer toxic chemicals than cigarettes-a statement backed by the US Surgeon General. ${ }^{1}$ In August 2016, the US Food and Drug Administration Center for Tobacco Products (US FDA CTP) was provided the authority to regulate the manufacturing, distribution, and marketing of ENDS in the USA. ${ }^{23}$ To inform their regulatory action, the US FDA CTP has specifically called for research that seeks to understand use behaviours and dependence in ENDS users. $^{4}$

ENDS use is high among American Indians and Alaskan Natives (AI/AN).${ }^{56}$ According to data from the 2014 US National Health Interview Survey, $11 \%$ of non-Hispanic AI/ AN adults currently use ENDS compared with $5 \%$ of non-Hispanic White adults. ${ }^{6}$ Since a commonly reported reason for using ENDS is to help quit or reduce cigarettes ${ }^{7-9}$ and AI/ ANs have a smoking prevalence higher than 
any other race group in the USA, ${ }^{10}$ high rates of dual use among AI/ANs might also be expected. Unpublished data from the 2014 Oklahoma Behavioral Risk Factor Surveillance Survey and the Adult Tobacco Survey showed that approximately $5.0 \%$ of AI/ANs are exclusive ENDS users and a further $8.5 \%$ are dual users compared with $3.2 \%$ and $4.0 \%$ of non-Hispanic Whites. A major public health question surrounding dual use is whether this behaviour will help or halt smoking cessation efforts. ${ }^{2}$

No information, to our knowledge, currently exists on use behaviours and dependence in ENDS users of AI/AN descent. To address this literature gap, we describe use behaviours and loss of autonomy, a core feature of dependence, in AI exclusive ENDS users and dual users of ENDS and cigarettes. Since cigarette smokers have been used as a comparison group in prior studies of ENDS, ${ }^{11-13}$ we also present data on exclusive cigarette smokers of AI descent. The results of this study will be significant for regulatory authorities, such as the US FDA CTP, and public health officials who are actively trying to understand ENDS use behaviour and dependence in priority populations such as AIs.

\section{METHODS}

\section{Participant recruitment}

From March to October 2016, community-based strategies were employed to recruit adults of AI descent who were in one of three groups of current tobacco use: (1) current exclusive cigarette smokers; (2) current exclusive ENDS users; and (3) concurrent users of cigarettes and ENDS, referred to as dual users. Recruitment strategies, previously described, ${ }^{14}$ included posting recruitment ads online and study staff attending cultural events, tribal health fairs and vape shops in the state of Oklahoma.

\section{Participant eligibility}

This study's inclusion and exclusion criteria were similar to those employed in a previous study of nicotine metabolism among AN tobacco users. ${ }^{15}$ All participants had to self-report AI race and at least two biological grandparents of AI race. Additionally, participants were between 18 and 65 years of age, and able to speak, read and write the English language. Additional inclusion criteria were employed to result in a sample of 'regular' users of cigarettes and/or ENDS. A regular cigarette smoker was defined as someone who has smoked at least five cigarettes per day for the past 3 months, smoked in the past 24 hours and not used tobacco products other than cigarettes in the past 3 months. A regular ENDS user was defined as someone who used an ENDS every day for the past 3 months and in the past 24 hours, and had not used tobacco products other than ENDS in the past 3 months. Although dual use refers to a heterogeneous group, we defined dual users as those who smoked at least five cigarettes per day in the past 3 months and in the past 24 hours, used an ENDS product every day for the past 3 months and in the past 24 hours, and not used tobacco products other than cigarettes and ENDS in the past 3 months.

Participants were excluded from any group if they regularly used medications for seizures, tuberculosis or cancer; were currently involved in a tobacco cessation programme or used nicotine replacement therapy; were pregnant or breast feeding; used illicit drugs in the 30 days prior to the study; and used alcohol or marijuana on the day of the study.

\section{Measures}

Data on age, gender, marital status, education level, employment status and body mass index were collected. Participants were also asked about their use of tobacco for sacred or ceremonial purposes (ie, traditional tobacco use), a practice common among some AI tribes. ${ }^{16-18}$

Since ENDS are relatively new to the marketplace and often called different names, the following statement, which was adapted from the US Population Assessment of Tobacco and Health, ${ }^{19}$ was read by ENDS and dual users prior to collecting information on ENDS use: 'You said you currently use an electronic nicotine product. These products are battery-powered, use nicotine fluid rather than tobacco leaves, and produce vapor instead of smoke. There are many different names for these devices. Some common brands include Fin, NJOY, Blu, e-Go and Vuse.' Generic photos ('cig-a-like'; tank or vapour system; e-cigar; e-pipe; e-hookah) of commonly used ENDS were displayed and participants chose the photo(s) which best resembled the ENDS they currently used. Participants had the option of choosing more than one. Participants were also asked if the ENDS was rechargeable, refillable with e-liquid, if it used cartridges and which nicotine concentration they currently used. Since ENDS users often use more than one flavour or mix flavours, participants reported all flavours they currently used.

There is not a standard or commonly accepted method for assessing frequency of ENDS use. ${ }^{2}$ In this study, ENDS and dual users read the following statement provided by the Ontario Tobacco Research Center to assess frequency of use: 'A session starts from your first puff and ends with your last puff before you take a break to do something else. A session can last for any length of time and involve any number of puffs, depending in the person. Sometimes these are called vape sessions.' Participants then responded to four questions: (1) 'How many sessions have you had with your electronic nicotine product in your lifetime?'; (2) 'In a typical day, how many sessions do you have?'; (3) 'How long does one session typically last for you?'; (4) 'How many puffs do you typically take per session?'. Other variables collected included age of ENDS initiation, age of regular ENDS initiation and duration of use. Among exclusive ENDS users, we asked if they were a never or former smoker. If they were a former smoker, we asked them to recall their number of cigarettes smoked per day (CPD) when smoked and the time since smoked. We also asked dual users to recall their number of CPD prior to ENDS initiation. 
There are a number of questionnaires with proven utility in assessing dependence to cigarettes. ${ }^{20-23}$ The Hooked on Nicotine Checklist (HONC), a 10-item screening tool, assesses of loss of autonomy in both adolescents and adults. ${ }^{23} 24$ Diminished autonomy is a core feature common to all forms of substance dependence, including tobacco dependence. ${ }^{24}$ HONC does not include measures on heaviness or frequency of use specific to cigarette smoking (eg, CPD). Thus, it can be readily modified to assess loss of autonomy to noncigarette tobacco products, such as ENDS. In the present study, loss of autonomy over cigarettes was summarised using both continuous scores $(0-10)$ and a dichotomous measure ( $0=$ fullautonomy; $\geq 1=$ diminished autonomy). We reworded the HONC to assess loss of autonomy to ENDS. Dual users completed the HONC twice, once with regard to cigarettes and once with regard to ENDS. Loss of autonomy over ENDS was also summarised using both continuous scores $(0-10)$ and a dichotomous measure ( 0 =full autonomy; $\geq 1$ =diminished autonomy).

Among dual users and exclusive smokers, measures of cigarette smoking were collected. These measures included the age when participants first tried part or all of a cigarette (ie, age of initiation), the age when participants started smoking cigarettes regularly (ie, age of regular initiation), average number of cigarettes currently smoked per day (CPD), duration of cigarette smoking, presence of a 24-hour quit attempt in the past 12 months and use of menthol cigarettes.

\section{Biochemical assessment of smoking status}

The measurement of exhaled carbon monoxide (CO) level provides an immediate, non-invasive assessment of cigarette smoking status. ${ }^{25} \mathrm{CO}$ was collected to biochemically confirm self-reported cigarette smoking status and therefore help reduce information bias. A CO value of $\geq 10$ parts per million (ppm) is commonly used to determine eligibility for studies among smokers. ${ }^{26-30}$ However, a borderline CO level between 6 and 9 ppm may also reflect cigarette smoking, or among non-smokers it may reflect exposure to second-hand smoke or other sources of CO (eg, car pollution). ${ }^{2531-33}$ Moreover, prior studies have required CO levels of $<6^{11}$ or $<10^{1234}$ for confirming exclusive ENDS use. Based on this information, we did not exclude individuals from any of the three groups with a $\mathrm{CO}$ between 6 and $9 \mathrm{ppm}$. Thus, ENDS users were included if they had a CO level $\leq 9 \mathrm{ppm}$, while cigarette smokers and dual users were included in the study if they had a CO level $\geq 6 \mathrm{ppm}$.

\section{Statistical analysis}

This study focused on describing characteristics of ENDS users, dual users and smokers of AI descent. Since the study's primary purpose was descriptive, a formal sample size calculation was not performed. Continuous and ordinal measures were described using median values and categorical measures were described by proportions. Scores and frequencies were compared between the three user groups with the non-parametric Kruskal-Wallis test for ordinal or continuous measures and with a $\chi^{2}$ test or Fisher's exact test for categorical measures. A P value $<0.05$ was considered statistically significant for comparison among all three user groups. Significant overall tests were followed by testing for differences between the three pairs of groups, and significance was assessed using a Bonferroni adjustment of alpha $=0.017$. Statistical analysis was conducted in SAS V.9.4.

\section{RESULTS}

A total of 95 individuals participated in the study: 28 ENDS users, 32 dual users and 35 cigarette smokers. Thirteen participants $(13.7 \%)$ were excluded because their $\mathrm{CO}$ values were outside the range for their given tobacco use group. Therefore, results are presented for the 82 participants (27 ENDS users, 28 dual users, 27 cigarette smokers) with $\mathrm{CO}$ values in the expected range given their self-reported tobacco use. Table 1 displays data on sociodemographic characteristics and traditional tobacco use for the 82 participants.

Table 2 presents data on ENDS use behaviours. Median age first tried an ENDS was 28.5 years among ENDS users and 35.0 years among dual users. Median age started using an ENDS regularly was 30.0 years among ENDS users and 36.5 years among dual users. Median duration of ENDS use was 2 years among ENDS users and 1 year among dual users. When prompted with the option to select the photo which best represented the ENDS currently being used, the vast majority of ENDS users (89\%) and dual users $(93 \%)$ selected a tank or vapour system. The vast majority, if not all, of ENDS users and dual users reported currently using an ENDS which was refillable with e-liquid $(89 \%, 100 \%)$ and rechargeable $(100 \%, 96 \%)$; while one-third or less $(30 \%, 33 \%)$ reported using cartridges. The majority of both ENDS users $(80 \%)$ and dual users $(69 \%)$ reported currently using a nicotine concentration of $12 \mathrm{mg}$ or less. More than one-half of ENDS and dual users reported using fruit $(67 \%, 54 \%)$ and candy $(52 \%$, $57 \%$ ) flavoured ENDS. Data on number of vape sessions in lifetime, vape sessions per day, puffs per vape session and length of vape session are also displayed in table 2 .

ENDS and dual users were asked questions to assess their smoking status prior to initiation of an ENDS (data not provided in tables). The vast majority of ENDS users $(92.6 \%)$ reported being former cigarette smokers. Among ENDS users who were former cigarette smokers, the median CPD when smoking was 20 and the median duration since smoked cigarettes was 2 years. Dual users were asked to recall CPD before initiation of an ENDS. Median CPD prior to ENDS use was 20, which was significantly higher than the current median of 15 CPD.

Table 3 presents data on cigarette smoking characteristics among dual users and exclusive smokers. Median CPD was 15 among dual users and 10 among smokers. The distribution of CPD did not differ between the two user groups. Distributions of age when respondents first 
Table 1 Sociodemographic characteristics and traditional tobacco use among all participants and by user group

\begin{tabular}{|c|c|c|c|c|c|}
\hline & $\begin{array}{l}\text { All participants } \\
(\mathrm{n}=82)\end{array}$ & $\begin{array}{l}\text { ENDS users } \\
(\mathrm{n}=27)\end{array}$ & $\begin{array}{l}\text { Dual users } \\
(\mathrm{n}=28)\end{array}$ & $\begin{array}{l}\text { Cigarette } \\
\text { smokers }(n=27)\end{array}$ & $P$ value \\
\hline Age, median & 41.5 & $33.0 \dagger$ & 41.0 & 46.0 & 0.0263 \\
\hline Gender, \% & & & & & 0.3592 \\
\hline Male & 37.8 & 29.6 & 35.7 & 48.2 & \\
\hline Female & 62.2 & 70.4 & 64.3 & 51.9 & \\
\hline Marital status, $\%$ & & & & & 0.1261 \\
\hline Married/member of unmarried couple & 42.7 & 44.4 & 28.6 & 55.6 & \\
\hline Never married/divorced/separated/widowed & 57.3 & 55.6 & 71.4 & 44.4 & \\
\hline Education level, \% & & & & & 0.2567 \\
\hline At least some college & 50.0 & 63.0 & 42.9 & 44.4 & \\
\hline High school diploma, GED or less & 50.0 & 37.0 & 57.1 & 55.6 & \\
\hline Employment status ${ }^{*} \%$ & & & & & 0.6162 \\
\hline Employed for wages/self-employed & 53.7 & 55.6 & 46.4 & 59.3 & \\
\hline Other & 46.3 & 44.4 & 53.6 & 40.7 & \\
\hline $\mathrm{BMI}\left(\mathrm{kg} / \mathrm{m}^{2}\right)$ category, $\%$ & & & & & 0.1333 \\
\hline Normal weight & 24.7 & 30.8 & 32.1 & 11.1 & \\
\hline Overweight or obese & 75.3 & 69.2 & 67.9 & 88.9 & \\
\hline Traditional/sacred tobacco use in past 3 months, $\%$ & & & & & 0.0366 \\
\hline Yes & 17.5 & 7.4 & 11.5 & 33.3 & \\
\hline No & 82.5 & 92.6 & 88.5 & 66.7 & \\
\hline
\end{tabular}

${ }^{*}$ Asked only to those who were employed for wages or self-employed.

†ENDS users significantly different from cigarette smokers at $P<0.05$.

$\mathrm{BMI}$, body mass index; ENDS, electronic nicotine delivery system; GED, general education diploma.

tried smoking a cigarette and started smoking cigarettes regularly did not differ between user groups. A greater proportion of dual users reported a 24-hour quit attempt in the previous 12 months than did smokers $(57 \%$ vs $26 \%$ ).

Table 4 presents data on the 10 individual items from the adapted HONC for loss of autonomy over ENDS. There were no differences in the individual HONC items when comparing ENDS with dual users. The proportion of ENDS users (64.3\%) who had a diminished autonomy over ENDS was no different than dual users $(77.8 \%)$. On a scale of $0-10$, median severity of diminished autonomy over ENDS was 4 and 3 among ENDS and dual users, respectively (figure 1). Distributions in severity of diminished autonomy over ENDS did not differ when comparing ENDS users with dual users. To further understand autonomy, loss of autonomy to ENDS in ENDS users was compared with loss of autonomy to cigarettes in smokers. There was no difference in proportions of diminished autonomy when comparing smokers with ENDS users $(96 \%$ vs $78 \%)$. However, distributions in severity of diminished autonomy differed. ENDS users had significantly lower scores for severity of diminished autonomy than smokers (4 vs 8 ). Furthermore, among dual users, severity of diminished autonomy over ENDS was lower than severity of diminished autonomy over cigarettes (3 vs 9 ).
The proportion of dual users $(100 \%)$ with diminished autonomy over cigarettes did not significantly differ from the proportion of cigarette smokers $(96.3 \%)$. Median severity of diminished autonomy over cigarettes was 9 and 8 among dual users and smokers, respectively. Distributions in severity of diminished autonomy over cigarettes did not differ when comparing dual users with smokers. When examining individual items measured by the HONC, a greater proportion of dual users than smokers said 'yes' to items 1 'Have you ever tried to quit cigarettes, but couldn't?' ( $79 \%$ vs 52\%; $\mathrm{P}=0.0372$ ) and 2 'Do you smoke now because it is really hard to quit smoking cigarettes?' ( $75 \%$ vs $48 \%$; $\mathrm{P}=0.0405$ ). There was no difference in items $3-10$.

\section{DISCUSSION}

This descriptive study provides novel findings about ENDS use in a small sample of AIs from Oklahoma, a state located in the Southern Plains region of the USA. Notably, this analysis was the first of its kind to provide an in-depth description of ENDS use, including both exclusive use and dual use with cigarettes, among AIs. Studies of this kind are a current research priority of the US FDA CTP, which serves as the regulatory authority for all tobacco products in the USA. ${ }^{45}$ Ultimately, this study provides a more complete picture of the current tobacco 
Table 2 Electronic nicotine delivery system (ENDS) use characteristics

\begin{tabular}{lcc}
\hline & $\begin{array}{l}\text { ENDS users } \\
\text { (n=27) }\end{array}$ & $\begin{array}{c}\text { Dual users } \\
\text { (n=28) }\end{array}$ \\
\hline Age of ENDS initiation, median & 28.5 & 35.0 \\
\hline $\begin{array}{l}\text { Age of regular ENDS initiation, } \\
\text { median }\end{array}$ & 30.0 & 36.5 \\
\hline $\begin{array}{l}\text { Duration of ENDS use, median } \\
\text { Type of ENDS: tank or vapour }\end{array}$ & 2.0 & 1.0 \\
system, \% & 88.9 & 92.9 \\
Type of ENDS: cig-a-like, \% & 7.4 & 21.4 \\
\hline Type of ENDS: e-cigar, \% & 0.0 & 3.6 \\
Type of ENDS: e-pipe, \% & 3.7 & 0.0 \\
\hline Type of ENDS: e-hookah, \% & 0.0 & 0.0 \\
ENDS is refillable, \% & 88.9 & 100.0 \\
\hline ENDS is rechargeable, \% & 100.0 & 96.4 \\
\hline ENDS uses cartridges, \% & 29.6 & 33.3
\end{tabular}

Nicotine concentration, \%

\begin{tabular}{|c|c|c|}
\hline $0 \mathrm{mg}$ & 0.0 & 7.7 \\
\hline $1-5 \mathrm{mg}$ & 52.0 & 30.8 \\
\hline $6-12 \mathrm{mg}$ & 28.0 & 30.8 \\
\hline $13-17 \mathrm{mg}$ & 8.0 & 3.9 \\
\hline $18-24 \mathrm{mg}$ & 8.0 & 23.1 \\
\hline $25 \mathrm{mg}$ or more & 4.0 & 3.9 \\
\hline Tobacco flavour, \% & 18.5 & 39.3 \\
\hline Menthol flavour, \% & 14.8 & 3.6 \\
\hline Clove or spice, \% & 7.4 & 17.9 \\
\hline Fruit, \% & 66.7 & 53.6 \\
\hline Chocolate, \% & 7.4 & 14.3 \\
\hline Alcoholic drink, \% & 3.6 & 0.0 \\
\hline Candy/sweets, \% & 51.9 & 57.1 \\
\hline Other flavour, \% & 11.1 & 21.4 \\
\hline \multicolumn{3}{|c|}{$\begin{array}{l}\text { Number of vape sessions in } \\
\text { lifetime*, \% }\end{array}$} \\
\hline 100 or less & 33.3 & 52.0 \\
\hline $101-200$ & 12.5 & 8.0 \\
\hline $201-300$ & 8.3 & 8.0 \\
\hline $301-400$ & 12.5 & 8.0 \\
\hline Over 400 & 33.3 & 24.0 \\
\hline \multicolumn{3}{|c|}{ Average number of vape sessions per day ${ }^{*} \%$} \\
\hline Less than 10 sessions & 28.0 & 52.0 \\
\hline 10-19 sessions & 44.0 & 20.0 \\
\hline 20-30 sessions & 16.0 & 8.0 \\
\hline Over 30 & 12.0 & 20.0 \\
\hline \multicolumn{3}{|c|}{ Average number of puffs per vape session ${ }^{\star}, \%$} \\
\hline Under 5 & 14.8 & 23.1 \\
\hline $5-10$ & 55.6 & 46.2 \\
\hline More than 10 & 29.6 & 30.8 \\
\hline
\end{tabular}

Continued
Table 2 Continued

ENDS users Dual users ( $n=27)$

$(n=28)$

Average length of vape session*, \%

$\begin{array}{lrl}1-2 \min & 33.3 & 25.0 \\ 3-5 \min & 40.7 & 28.6 \\ 6-10 \min & 18.5 & 25.0 \\ \text { Over } 10 \min & 7.1 & 21.4\end{array}$

${ }^{*}$ Provided by the Ontario Tobacco Research Center.

use landscape and will be informative for our future research on biomarkers of exposure in this population, as well as for guiding regulatory authorities who are working to understand the impact of ENDS on public health in both general and disparate populations.

ENDS are part of the diversifying tobacco and nicotine landscape. ${ }^{36}$ Currently, there are several gaps in how to define and classify these devices making research on ENDS difficult. ${ }^{2}$ Understanding characteristics of ENDS (eg, type of device, nicotine concentration and flavour of e-liquid) is important as these characteristics have been shown to influence use behaviour. ${ }^{12}$ Thus, a major strength of the present study was the number of characteristics collected on ENDS use and the usage of pictures to aid participants in selecting which product they currently used. The vast majority of ENDS and dual users in this sample reported using a tank or vapour system. Additionally, most reported that their ENDS was refillable with e-liquid and rechargeable. The majority of both dual and ENDS users reported using ENDS with nicotine concentrations of $12 \mathrm{mg}$ or less. These findings are consistent with other epidemiologic surveys that have identified rechargeable and refillable devices to more popular among ENDS users than cartridge-based or disposable ENDS. $^{1237}$

Table 3 Cigarette smoking characteristics among cigarette dual users and smokers

\begin{tabular}{|c|c|c|}
\hline & $\begin{array}{l}\text { Dual users } \\
(n=28)\end{array}$ & $\begin{array}{l}\text { Cigarette } \\
\text { smokers } \\
(n=27)\end{array}$ \\
\hline Cigarettes per day, median & 15.0 & 10.0 \\
\hline \multicolumn{3}{|l|}{ Cigarettes per day, \% } \\
\hline$<1$ pack & 57.1 & 59.3 \\
\hline$\geq 1$ pack & 42.9 & 40.7 \\
\hline Age of initiation, median & 15.0 & 14.0 \\
\hline Age of regular initiation, median & 16.5 & 19.0 \\
\hline Duration of smoking, median & 21.5 & 26.0 \\
\hline $\begin{array}{l}\text { 24-hour smoking quit attempt in } \\
\text { past } 12 \text { months, } \%\end{array}$ & $57.1^{*}$ & 25.9 \\
\hline Smokes mentholated cigarettes, \% & 21.4 & 40.7 \\
\hline
\end{tabular}

*Dual users significantly different from cigarette smokers at $\mathrm{P}<0.05$. 
Table 4 Results from Hooked on Nicotine Checklist for assessing loss of autonomy over cigarettes and adapted version for assessing loss of autonomy over electronic nicotine delivery systems (ENDS)*

\begin{tabular}{|c|c|c|c|c|}
\hline & $\begin{array}{l}\text { ENDS } \\
\text { users } \\
(n=27)\end{array}$ & \multicolumn{2}{|c|}{$\begin{array}{l}\text { Dual users } \\
(n=28)\end{array}$} & $\begin{array}{l}\text { Cigarette } \\
\text { smokers } \\
(n=27)\end{array}$ \\
\hline & \multicolumn{2}{|c|}{ Over ENDS } & \multicolumn{2}{|c|}{ Over cigarettes } \\
\hline \multicolumn{5}{|l|}{ Individual items measured in HONC, \% } \\
\hline 1. Have you ever tried to quit cigarettes (using an ENDS), but couldn't? & 18.5 & 18.5 & 78.6 & 51.9 \\
\hline $\begin{array}{l}\text { 2. Do you smoke (use your ENDS) now because it is really hard to quit smoking } \\
\text { cigarettes (using an ENDS)? }\end{array}$ & 32.1 & 40.7 & 75.0 & 48.2 \\
\hline 3. Have you ever felt like you were addicted to cigarettes (an ENDS)? & 28.6 & 37.0 & 82.1 & 70.4 \\
\hline 4. Do you ever have strong cravings to smoke (use an ENDS)? & 50.0 & 59.3 & 96.4 & 85.2 \\
\hline 5. Have you ever felt like you really needed a cigarette (an ENDS)? & 57.1 & 59.3 & 100.0 & 92.6 \\
\hline $\begin{array}{l}\text { 6. Is it hard to keep from smoking (using an ENDS) in places where you are not } \\
\text { supposed to? }\end{array}$ & 35.7 & 25.9 & 53.6 & 44.4 \\
\hline \multicolumn{5}{|l|}{$\begin{array}{l}\text { When you haven't smoked cigarettes (used an ENDS) for a while OR } \\
\text { When you tried to stop smoking cigarettes (using an ENDS)... }\end{array}$} \\
\hline $\begin{array}{l}\text { 7. ... did you find it hard to concentrate because you couldn't smoke a cigarette (use } \\
\text { an ENDS)? }\end{array}$ & 28.6 & 22.2 & 57.1 & 38.5 \\
\hline $\begin{array}{l}\text { 8. ... do you feel more irritable because you couldn't smoke a cigarette (use an } \\
\text { ENDS)? }\end{array}$ & 25.0 & 48.2 & 71.4 & 74.1 \\
\hline 9. ... did you feel a strong need or urge to smoke a cigarette (use an ENDS)? & 57.1 & 59.3 & 89.3 & 81.5 \\
\hline $\begin{array}{l}\text { 10. ...did you feel nervous, restless, or anxious because you couldn't smoke a } \\
\text { cigarette (use an ENDS)? }\end{array}$ & 28.6 & 37.0 & 75.0 & 55.6 \\
\hline
\end{tabular}

*Substitute the italicized word with the words in parenthesis for assessing loss of autonomy over ENDS.

Concern surrounds flavoured tobacco products as they have been disproportionately used by youth and initiators. ${ }^{38-40}$ Due to this, flavoured cigarettes, excluding menthol flavour, were prohibited in the USA in 2009 as part of the landmark Family Smoking Prevention and Tobacco Control Act. ${ }^{41}$ Currently, ENDS, or the e-liquid

- Severity of diminished autonomy over ENDS

- Severity of diminished autonomy over cigarettes

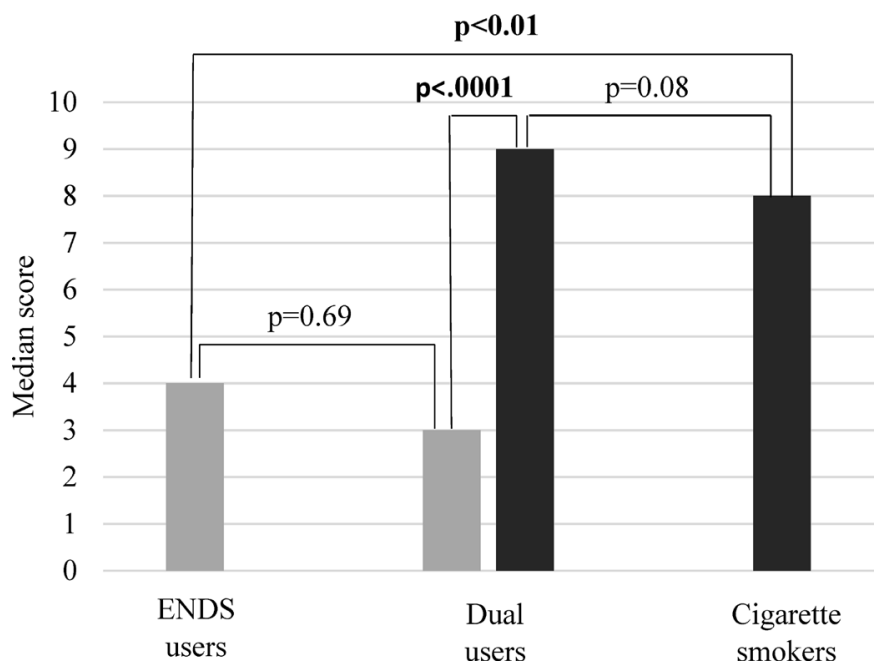

Figure 1 Median severity of diminished autonomy over electronic nicotine delivery systems (ENDS) and/or cigarettes. used in ENDS, come in a variety of flavours. One study identified nearly 8000 flavours available online and showed that the vast majority of brands offered fruit, candy and dessert flavours. ${ }^{42}$ Flavours are a commonly cited reason for vaping, particularly in youth and young adults. ${ }^{843-46}$ In the present study, the most common flavours among both ENDS and dual users were fruit and candy or sweets. Other studies have also found fruit and candy flavours to be popular among ENDS users. ${ }^{47} 48$ None of the participants in the present study reported not using any flavour. Regulatory authorities need to consider the potential impact of eliminating flavours in ENDS, as their prohibition, especially fruit and candy flavours, will reduce youth appeal and the appeal to adult ENDS users.

Data on patterns of ENDS use are crucial for understanding the impact of these devices on public health, especially among priority populations disproportionately affected by tobacco use. There are no standardised methods for assessing ENDS behaviour. In the present study, participants read a generic definition of a 'vape session' and then were asked questions to characterise vape sessions. One-third of ENDS users and more than half of dual users reported 100 or less vape sessions in their lifetime. This is surprising since ENDS were used for a median duration of 1 or 2 years and the study eligibility which included using an ENDS every day in the past 3 months. Participants may have had a hard time recalling this number and simply guessed or perhaps the question 
was worded in a manner that caused confusion. Another explanation is the participants may have underestimated their total number of vape sessions as a result of social desirability. Cognitive testing of this measure should be pursued among an adequately powered sample. Average number of vape sessions per day varied, with most reporting less than 20 sessions per day. An average of 5-10 puffs per vape session was most common among both ENDS and dual users. In terms of vape sessions, most lasted for 5 min or less among ENDS users; while the proportion of dual users who reported a vape session lasting 1-2, 3-5, 6-10 and over $10 \mathrm{~min}$ were similar. In addition to providing a deeper understanding of ENDS use among AIs, these findings are relevant for researchers seeking to understand which measures should be used to monitor patterns of ENDS use.

Attempts to quit smoking are considered a critical step to increasing rates of smoking cessation and, subsequently, reducing the smoking prevalence ${ }^{104950}$ Based on data from the 2013 National Health Interview Survey, an estimated $51 \%$ of AI smokers reported attempting to quit in the past 12 months. ${ }^{51}$ In the present study, the proportion of dual users who made a quit attempt was more than twice the proportion among exclusive smokers. This finding supports previous literature linking ENDS use to smoking cessation. For example, in a nationally representative sample of US cigarette smokers $(\mathrm{n}=2028)$, ENDS users had a higher smoking quit attempt ( $73 \%$ vs $46 \%$ ) and cessation $(42 \%$ vs $16 \%)$ rate than non-ENDS users. ${ }^{52}$ We did not ask participants about their reason for using ENDS; however, there is a possibility that dual users in the present study are similar to those in other studies who report using ENDS to quit cigarettes. ${ }^{7-9}$ Dual users were asked to recall their average CPD before ENDS initiation, which was significantly higher than their current CPD. Additionally, although there was no difference in proportion of overall loss of autonomy measures, a higher proportion of dual users than smokers said 'yes' to items 1 and 2 on the HONC, both of which contain language related to quitting smoking. This observation supports the finding that a higher proportion of dual users than smokers made a smoking quit attempt. Future cohort studies, such as the US Population Assessment of Tobacco Use and Health, are needed to assess the causal relationship between dual use and smoking cessation.

A major component of assessing the public health impact of ENDS use is to understand the dependence potential in both exclusive and dual users. Since ENDS and cigarettes differ in patterns of use, methods for assessing dependence that can facilitate comparison across products are needed. In the present study, HONC was used to assess diminished autonomy-a core feature of tobacco dependence. ${ }^{24}$ With median scores of 4 and 3, ENDS and dual users were no different in loss of autonomy over ENDS. Eissenberg and colleagues recently developed a questionnaire, which contained measures from a variety of scales including the HONC, to assess dependence to both cigarettes and ENDS. ${ }^{13}$
Eissenberg found ENDS users to be less dependent on ENDS than they retrospectively reported having been dependent on cigarettes prior to switching. ${ }^{13}$ Although we did not ask ENDS users who were former smokers to recall their loss of autonomy to cigarettes, severity of loss of autonomy in ENDS users was one-half of the severity of loss of autonomy in smokers. Future research comparing dependence scores in ENDS users and smokers while controlling for potential confounding factors, such as age, is needed.

\section{Limitations}

Although this study has the potential to provide important information, it must be considered in light of its limitations. The focus of this study was not on testing of hypotheses, but on describing characteristics of ENDS users, dual users and smokers of AI descent. Thus, we did not incorporate a formal sample size calculation. The small sample size restricted our ability to control for potential confounders (eg, gender, age), which have been shown to influence tobacco use behaviours and dependence scores. The reason for this study was to determine the feasibility of recruiting AI research participants and collecting data on their ENDS behaviour. The plan is to expand this study by recruiting a larger sample of ENDS users of AI descent and other race groups (eg, whites, blacks) for comparison purposes. Second, the study population was not randomly sampled, rather participants were enrolled based on convenience using community-based recruitment strategies. Therefore, generalisations to all AIs, including those residing in Oklahoma, should be made with caution. Also, the exclusion criteria may further impact the ability to generalise findings. Of most concern is that individuals who used alcohol on the day of the study were not eligible. Alcohol use is correlated with tobacco use $\mathrm{e}^{5354}$; thus restricting eligibility to those who did not consume alcohol may harm the external validity of the findings. Third, this study relied on self-report and thus prone to recall bias. Lastly, several of the ENDS measures (eg, adapted version of HONC) have yet to be validated. Future studies should be conducted to determine the sensitivity and specificity of these measures.

\section{CONCLUSION}

This study provides an in-depth description of ENDS use, including both exclusive use and dual use with cigarettes, among AIs. Ultimately, this study helps provide a more complete picture of the current tobacco use landscape among AIs and will be informative for regulators as well as public health officials who are actively trying to understand behaviour and dependence among ENDS users.

Acknowledgements We are deeply grateful for the support of the Southern Plains Tribal Health Board, the many tribal communities, and vape shops that helped make this research a success. 
Contributors Conceptualisation: DMC, TLW, DMT, LDS, JDP, JEC, LAB. Funding acquisition: DMC, TLW, LAB. Methodology: DMC, TLW, DMT, LDS, JDP, JEC, LAB. Project administration: DMC, LAB. Supervision: TLW, DMT, LDS, JDP, JEC, LAB. Data analysis: DMC, LAB. Writing of original draft: DMC, LAB. Review and editing: DMC, TLW, DMT, LDS, JDP, JEC, LAB.

Funding This work was supported by the National Institute on Drug Abuse at the National Institutes of Health (grant number 1R36DA042208-01). Facility support has been provided by the Oklahoma Shared Clinical and Translational Resources (grant number U54GM104938)

Competing interests None declared.

Ethics approval University of Oklahoma Health Sciences Center (No. 6317) and the Oklahoma City Area Indian Health Service Institutional Review Board (No. P-16-01-0K).

Provenance and peer review Not commissioned; externally peer reviewed. Data sharing statement № additional data available.

Open Access This is an Open Access article distributed in accordance with the Creative Commons Attribution Non Commercial (CC BY-NC 4.0) license, which permits others to distribute, remix, adapt, build upon this work non-commercially, and license their derivative works on different terms, provided the original work is properly cited and the use is non-commercial. See: http://creativecommons.org/ licenses/by-nc/4.0/

C Article author(s) (or their employer(s) unless otherwise stated in the text of the article) 2017. All rights reserved. No commercial use is permitted unless otherwise expressly granted.

\section{REFERENCES}

1. US Department of Human and Health Services. E-Cigarette use among youth and young adults. A report of the Surgeon General. Atlanta, GA: US Department of Health and Human Services, Centers for Disease Control and Prevention, National Center for Chronic Disease Prevention and Health Promotion, Office on Smoking and Health, 2016.

2. Walton KM, Abrams DB, Bailey WC, et al. NIH electronic cigarette workshop: developing a research agenda. Nicotine Tob Res 2015;17:259-69.

3. Chen IL. FDA summary of adverse events on electronic cigarettes. Nicotine Tob Res 2013;15:615-6.

4. National Institutes of Health, Office of Disease Prevention. FDA center for tobacco products research interest areas. https:// prevention.nih.gov/tobacco-regulatory-science-program/researchpriorities (accessed May 2015).

5. Schmidt L, Reidmohr A, Harwell TS, et al. Prevalence and reasons for initiating use of electronic cigarettes among adults in Montana, 2013. Prev Chronic Dis 2014;11:E204.

6. Schoenborn CA, Gindi RM. Electronic cigarette use among adults: United States, 2014. NCHS data brief 2015;217:1-8.

7. Wong LP, Mohamad Shakir SM, Alias H, et al. Reasons for using electronic cigarettes and intentions to quit among electronic cigarette users in Malaysia. $J$ Community Health 2016;41:1101-9.

8. Rutten LJ, Blake KD, Agunwamba AA, et al. Use of E-Cigarettes among current smokers: associations among reasons for use, quit intentions, and current tobacco use. Nicotine Tob Res 2015;17:1228-34.

9. Dawkins L, Turner J, Roberts A, et al. 'Vaping' profiles and preferences: an online survey of electronic cigarette users. Addiction 2013:108:1115-25.

10. US Department of Health, Human Services. The health consequences of smoking -50 years of progress: a report of the surgeon general. Atlanta, GA: US Department of Health and Human Services, Centers for Disease Control and Prevention, National Center for Chronic Disease Prevention and Health Promotion, Office on Smoking and Health. 2014;17.

11. Hecht SS, Carmella SG, Kotandeniya D, et al. Evaluation of toxicant and carcinogen metabolites in the urine of e-cigarette users versus cigarette smokers. Nicotine Tob Res 2015;17:704-9.

12. Wagener TL, Floyd EL, Stepanov I, et al. Have combustible cigarettes met their match? The nicotine delivery profiles and harmful constituent exposures of second-generation and third-generation electronic cigarette users. Tob Control 2017;26:e23-8.

13. Foulds $\mathrm{J}$, Veldheer $\mathrm{S}$, Yingst $\mathrm{J}$, et al. Development of a questionnaire for assessing dependence on electronic cigarettes among a large sample of ex-smoking E-cigarette users. Nicotine Tob Res 2015;17:186-92.
14. Carroll DM, Brame LS, Stephens LD, et al. Community-based study recruitment of American Indian cigarette smokers and electronic cigarette users. J Community Health 2017.

15. Renner CC, Lanier AP, Lindgren B, et al. Tobacco use among southwestern Alaska Native people. Nicotine Tob Res 2013;15:401-6.

16. U.S. Department of Health and Human Services. Tobacco use among U.S. racial/ethnic minority groups-African Americans, American Indians and Alaska natives, Asian Americans and Pacific Islanders, and Hispanics: a report of the surgeon general. Atlanta, Georgia: US Department of Health and Human Services, Centers for Disease Control and Prevention, National Center for Chronic Disease Prevention and Health Promotion, Office on Smoking and Health, 1998.

17. Eichner JE, Cravatt K, Beebe LA, et al. Tobacco use among American Indians in Oklahoma: an epidemiologic view. Public Health Rep 2005;120:192-9.

18. Tobacco Education and Prevention Technical Support Center, California Rural Indian Health Board. Commerical tobacco 101 and traditional tobacco use community tobacco educators training: learing module. http://www.keepitsacred.org/wp-content/ uploads/sites/5/2015/06/CRIHB-Commercial-Tobacco-101.pdf (accessed 4 Nov 2015).

19. National Institutes of Health's National Institute on Drug Abuse (NIH/NIDA), Food and Drug Administration (FDA). PATH Study Data Collection Instruments. file:///C:/Users/dmowls/Downloads/2_PATH Study_Data_Collection_Instruments\%20(4).pdf (accessed 29 Nov 2016).

20. Kozlowski LT, Porter CQ, Orleans CT, et al. Predicting smoking cessation with self-reported measures of nicotine dependence: FTQ, FTND, and HSI. Drug Alcohol Depend 1994;34:211-6.

21. Heatherton TF, Kozlowski LT, Frecker RC, et al. The fagerström test for nicotine dependence: a revision of the fagerström tolerance questionnaire. Br J Addict 1991;86:1119-27.

22. Piper ME, McCarthy DE, Bolt DM, et al. Assessing dimensions of nicotine dependence: an evaluation of the Nicotine Dependence Syndrome Scale (NDSS) and the Wisconsin Inventory of Smoking Dependence Motives (WISDM). Nicotine Tob Res 2008;10:1009-20.

23. DiFranza JR, Savageau JA, Fletcher K, et al. Measuring the loss of autonomy over nicotine use in adolescents: the DANDY (Development and Assessment of Nicotine Dependence in Youths) study. Arch Pediatr Adolesc Med 2002;156:397-403.

24. Wellman RJ, DiFranza JR, Savageau JA, et al. Measuring adults' loss of autonomy over nicotine use: the Hooked on Nicotine Checklist. Nicotine Tob Res 2005;7:157-61.

25. Deveci SE, Deveci F, Açik Y, et al. The measurement of exhaled carbon monoxide in healthy smokers and non-smokers. Respir Med 2004;98:551-6.

26. Polosa R, Caponnetto P, Maglia M, et al. Success rates with nicotine personal vaporizers: a prospective 6-month pilot study of smokers not intending to quit. BMC Public Health 2014;14:1159.

27. Lerman C, Schnoll RA, Hawk LW, et al. Use of the nicotine metabolite ratio as a genetically informed biomarker of response to nicotine patch or varenicline for smoking cessation: a randomised, doubleblind placebo-controlled trial. Lancet Respir Med 2015;3:131-8.

28. Jorenby DE, Smith SS, Fiore MC, et al. Varying nicotine patch dose and type of smoking cessation counseling. JAMA 1995;274:1347-52.

29. Anthenelli RM, Benowitz NL, West R, et al. Neuropsychiatric safety and efficacy of varenicline, bupropion, and nicotine patch in smokers with and without psychiatric disorders (EAGLES): a double-blind, randomised, placebo-controlled clinical trial. Lancet 2016;387:2507-20.

30. Benowitz NL, III PJ, Ahijevych K, et al. Biochemical verification of tobacco use and cessation. Nicotine Tob Res 2002;4:149-59.

31. Jarvis MJ, Tunstall-Pedoe H, Feyerabend C, et al. Comparison of tests used to distinguish smokers from nonsmokers. Am J Public Health 1987;77:1435-8.

32. Middleton ET, Morice AH. Breath carbon monoxide as an indication of smoking habit. Chest 2000;117:758-63.

33. Covita Smokerlyzer for use with Micro + Pro user manual. https:// covita.net/assets/micro-pro-manual-issue-1.pdf (accessed $25 \mathrm{Apr}$ 2017).

34. Shahab L, Goniewicz ML, Blount BC, et al. Nicotine, carcinogen, and toxin exposure in long-term E-cigarette and nicotine replacement therapy users: a cross-sectional study. Ann Intern Med 2017;166:390-400.

35. U.S. Food and Drug Administration. FDA's new regulations for E-cigarattes, cigares, and ALL OTHER TOBACCO PRODUCTS. Extending authorities to all tobacco products, including E-cigarettes, cigars, and hookah. https://www.fda.gov/TobaccoPr 
oducts/Labeling/RulesRegulationsGuidance/ucm394909.htm (accessed Nov 2017)

36. Centers for Disease Control and Prevention. E-cigarettes: an emerging public health challenge Public Health Grand Rounds 2015. http://www.cdc.gov/cdcgrandrounds/archives/2015/october2015. htm (accessed 6 Oct 2015).

37. Coleman BN, Rostron B, Johnson SE, et al. Electronic cigarette use among US adults in the population assessment of tobacco and health (PATH) study, 2013-2014. Tob Control 2017;2017:1-10.

38. US Department of Human and Health Services. Preventing tobacco use among youth and young adults: a report of the Surgeon General. Atlanta, GA: US Department of Health and Human Services, Centers for Disease Control and Prevention, National Center for Chronic Disease Prevention and Health Promotion, Office on Smoking and Health, 2012

39. Campaign for Tobacco-Free Kids. Electronic cigarettes and youth. http://www.tobaccofreekids.org/research/factsheets/pdf/0382.pdf (accessed 28 Nov 2016).

40. Klein SM, Giovino GA, Barker DC, et al. Use of flavored cigarettes among older adolescent and adult smokers: united States, 20042005. Nicotine Tob Res 2008;10:1209-14.

41. Food US and Drug Administration (FDA). Candy and fruit flavored cigarettes now illegal in united states; step is first under new tobacco Law. http://www.fda.gov/NewsEvents/Newsroom/ PressAnnouncements/ucm183211.htm (accessed 28 Nov 2016).

42. Zhu SH, Sun JY, Bonnevie E, et al. Four hundred and sixty brands of e-cigarettes and counting: implications for product regulation. Tob Control 2014;23(Suppl 3):iii3-9.

43. Farsalinos KE, Romagna G, Voudris V. Factors associated with dual use of tobacco and electronic cigarettes: A case control study. Int $J$ Drug Policy 2015;26:595-600.

44. Kong G, Morean ME, Cavallo DA, et al. Reasons for electronic cigarette experimentation and discontinuation among adolescents and young adults. Nicotine Tob Res 2015;17:847-54.
45. Ambrose BK, Day HR, Rostron B, et al. Flavored tobacco product use among us youth aged 12-17 years, 2013-2014. JAMA 2015;314:1871-3.

46. Villanti AC, Johnson AL, Ambrose BK, et al. Flavored tobacco product use in youth and adults: findings from the first wave of the PATH study (2013-2014). Am J Prev Med 2017;53:139-51.

47. Berg CJ. Preferred flavors and reasons for e-cigarette use and discontinued use among never, current, and former smokers. Int $J$ Public Health 2016;61:225-36.

48. Harrell MB, Weaver SR, Loukas A, et al. Flavored e-cigarette use: characterizing youth, young adult, and adult users. Prev Med Rep 2017;5:33-40.

49. Hymowitz N, Cummings KM, Hyland A, et al. Predictors of smoking cessation in a cohort of adult smokers followed for five years. Tob Control 1997;6(Suppl 2):S57-62.

50. Zhou X, Nonnemaker J, Sherrill B, et al. Attempts to quit smoking and relapse: factors associated with success or failure from the ATTEMPT cohort study. Addict Behav 2009;34:365-73.

51. Office of Disease Prevention and Health Promotion, Centers for Disease Control and Prevention. Disparities details by race and ethnicity for 2012. 2013. http://www.healthypeople.gov/2020/data/ disparities/detail/Chart/5359/3/2012

52. Zhuang YL, Cummins SE, Sun JY, et al. Long-term e-cigarette use and smoking cessation: a longitudinal study with US population. Tob Control 2016;25(Suppl 1):i90-5.

53. Whitesell NR, Beals J, Crow CB, et al. Epidemiology and etiology of substance use among American Indians and Alaska Natives: risk, protection, and implications for prevention. Am J Drug Alcohol Abuse 2012;38:376-82.

54. Falk DE, Yi HY, Hiller-Sturmhöfel S. An epidemiologic analysis of co-occurring alcohol and tobacco use and disorders: findings from the national epidemiologic survey on alcohol and related conditions. Alcohol Res Health 2006;29:162-71. 